\title{
Claire Stevens: 'If we get it right from birth, there is a chance we can raise this generation free of dental decay'
}

Interview by Adrian O'Dowd

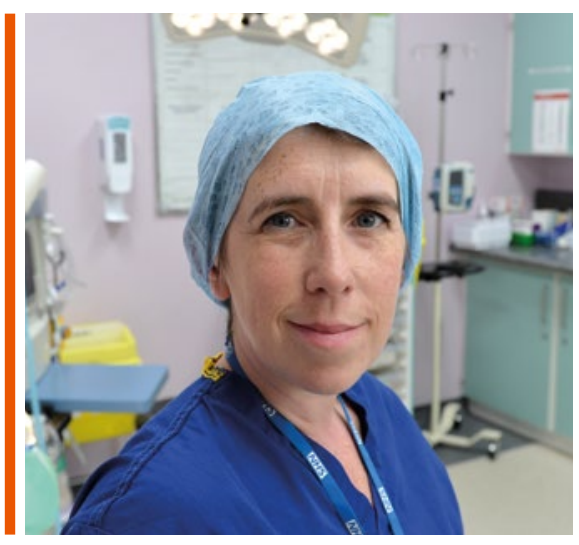

\section{Why are so many children still being admitted to hospital for tooth extractions?}

What we are seeing at the minute is almost the effects of decisions made over five years ago. The children that are coming in to see us to have multiple teeth removed have not had the benefits of the recent efforts to improve children's oral health.

Fortunately, we now have an understanding, which is going across organisations and across professions, that the focus needs to be on prevention, but it's not a quick fix.

There is lots of positive change at the minute. Things like Smile 4 Life and Starting Well are hugely positive initiatives and I am confident that we will see the benefits in due course, but it's not going to happen within a year.

Across the country, Trusts will be making efforts to reduce their waiting lists. For example, in Greater Manchester, our numbers of general anaesthetics have gone up even though children's oral health has improved because we're trying to reduce the amount of time that children are waiting for an operation.

If you just look at the figures, I think they will get worse before they get better, but I

Claire Stevens CBE is a NHS consultant in paediatric dentistry, children's oral health lead at the Greater Manchester Health and Social Care Partnership and immediate past president of the British Society of Paediatric Dentistry as well as its media spokesperson.

am confident that we are starting to put in place measures that will see those numbers of children needing a general anaesthetic to remove multiple teeth falling. We need to be clear that it is about reducing the numbers of children that need this procedure, not artificially reducing the numbers of operations by restricting access to general anaesthetic services.

\section{Is there a lack of awareness amongst parents over how quickly children should be seeing a dentist?}

We launched a campaign in September 2017 for parents to get their children in to see the dentist as soon as teeth come through or by their first birthday - Dental Check by One. We knew that some parents were confused about when to first take a child to the dentist and amongst the profession, we weren't giving out a consistent message. Now the message is coming out loud and clear about Dental Check by One.

Within six months of the campaign, the Royal College of Paediatrics and Child Health (RCPCH) commissioned a survey with Mumsnet that showed that $50 \%$ of parents were aware of Dental Check by One and that was only six months in. It's still a work in progress. Dental Check by One was the focus of my presidential year but I continue to spread that message wherever I can - engaging with paediatricians, nurses, including school nurses and health visitors.

For me it's not just about dentists speaking to dentists, but dentists speaking to the whole team and to anyone who might come into contact with that child. We need to make every contact count. Many of the interventions that we have in place in Greater Manchester aren't delivered by the dental team. Health visitors distribute free toothbrushes and toothpastes and deliver key oral health messages at six months and $2^{1 / 2}$ years because they are the professionals who are working most closely with the families at that age. It's about integrating oral health messages into general health messages.

Is the success of children-themed oral health improvement campaigns such as the Starting Well initiative patchy across the country?

The Starting Well areas are the areas of highest dental need. It is right that the health of these children is prioritised if we wish to reduce persistent inequalities in children's oral health. In Greater Manchester, we have 
doubled the national average of 0 to 2 -yearold children that have seen a NHS dentist in the last year. That is hugely positive.

What it shows me is that when we have that focus and when there's a whole system approach to support it and people understand why it's important and they are geared
We don't want to be alarmist and we don't want to have families thinking they can't come in to see us with their child who has a hole in their tooth because we're going to call children's services. The research highlighted the role that dental professionals have as part of that network of care and to be sharing any

\section{'For dentistry as a whole, we have become more confident in terms of our role within safeguarding and we are more confident that it always needs to be on our radar'}

up to deliver it, change is possible. When BSPD started Dental Check by One, a lot of people said it wouldn't happen and that GDPs wouldn't be supportive as they don't feel comfortable treating young children.

I found the reverse to be true. We couldn't have had more support from the profession. Everyone has seen that this is something we can get behind. We have had unprecedented cross-organisational support for Dental Check by One. If we get it right from birth, there is a chance we can raise this generation free of dental decay. The 13 areas of Starting Well are an example of what can be achieved, but I would like to see an expansion of the scheme so that every child can access preventively focused dental care, irrespective of postcode.

\section{Does it surprise you that recent research found dental neglect can be an indicator of wider neglect in children?}

I am an NHS consultant in paediatric dentistry and I am seeing the most extreme cases in terms of decay experience, so for me this did not come as a surprise.

For dentistry as a whole, we have become more confident in terms of our role within safeguarding and we are more confident that it always needs to be on our radar. We know that dental caries does not equal neglect but we also know that when there is a delay in presentation of dental decay and when it's particularly severe and there's clear evidence of unmet dental needs, then we need to think what else is going on in that family? There is a fantastic resource on the BDA's website on child protection by BSPD's Jenny Harris. I regularly encourage colleagues to go back and refresh their training. information that we have with other health professionals that might have contact with that child and not working in isolation.

It's important that information sharing goes the other way as well so when a child has a safeguarding assessment, as part of that, someone should say what about the teeth and does the child have unmet dental needs? As dentists, we need to make that process easy.

In Greater Manchester, we have got an abridged version of our electronic referral form which has been designed with paediatricians so that they can refer their patients straight into the paediatric dental care pathway. It's joined up communication.

Over the past year, food manufacturers have been reprimanded by the Advertising Standards Authority over how they promote products to children - is it just a matter of time before manufacturers get the message that they have to be more careful about marketing products?

It will take time. For those of us that are campaigning for ethical marketing and clear and consistent labelling [of foods and drinks], we sugar product with the festive season, for example.

It's a consistent message from all health professionals. For those who are concerned about obesity, there are often also concerns about the same things from those who are also looking to improve oral health.

The Sugar Smart campaign last year coordinated by Sustain had over 80 organisations as signatories asking Coca-Cola not to hand out sugary drinks. It had an effect.

\section{Has investing in oral health by the Greater Manchester Health and Social Care Partnership made a difference?}

Absolutely. We have invested $£ 1.5$ million in a regional programme of prevention. We are delivering supervised brushing in early year settings and health visitors are giving out dental packs in four out of our ten areas. These are evidence-based interventions that we know deliver a return on investment. Paediatric dentists were right at the heart of calling for these interventions, working with our consultants in dental public health, commissioners and oral health promotion teams. Working in Greater Manchester, with our devolved health and social care budget, allows clinicians to lead change at pace.

I feel extremely privileged to be part of such a forward thinking system where my voice and my role as a clinical leader is valued and supported and where I am able to have a reach that is far greater than my day to day job as an NHS consultant. The role of the consultant is changing. Increasingly, we are seen as experts in our local health population and clinical leaders. When we wrote our population health plan, it had a very clear ambition to improve children's oral health through delivering preventatively focused services with every

\section{'For those who are concerned about obesity, there are often also concerns about the same things from those who are also looking to improve oral health'}

have a coordinated plan and message to go to manufacturers. What has been good this year is that the public have joined with health professionals on certain messages - please don't confuse the marketing of your high child accessing those before their first birthday.

Dental Check by One is in our population health plan for Greater Manchester and we made sure it was in the Mayor's manifesto. 
There's an air of confidence and a 'can-do' attitude here.

We want to be seen as leaders and at the forefront of changing the way that we deliver children's oral health. We have got to look at different ways of doing it. The trust that I work in has seen a $70 \%$ increase in referrals over three years so you can see that that is not sustainable, especially as we don't have enough paediatric dentists. There are far fewer paediatric dentists than the other dental specialists yet the need for our services is high. We don't have the manpower to be able to do things in a conventional way so we need to explore innovative ways of delivering key prevention messages. I believe that digital innovations have a role to play and this is something we are actively exploring in Greater Manchester.

and people that you might not otherwise meet.

I had a different theme each day - I spoke about Dental Check by One, general anaesthetics, fluoridation, the role of different healthcare professionals, for example. The engagement and feedback I had was absolutely phenomenal.

I formed some good connections. When I first qualified, I was taught to never engage with the media. Clearly I have not followed that advice! The reach that I can get through social media is far greater than I can in my day to day work.

For the five days that I curated the NHS Twitter account, my reach was not far off a million interactions, whereas, however busy you are as a consultant, you are not going to see that many patients in a year or

\section{'For the five days that I curated the NHS Twitter account, my reach was not far off a million interactions, whereas, however busy you are as a consultant, you are not going to see that many patients in a year or even a lifetime!'}

\section{Is it important to lobby on the issue of child oral health?}

Yes. That's something I have tried to do during and after my presidential term. Lobbying and political support is important but it needs to be coordinated. What you need is coordinated action and agreeing what we are asking for and how it's going to work and then everybody asking for the same thing. That is far more powerful. Also including the patient and parent voice is increasingly important and we will see more of that in the future.

\section{What was it like taking over the NHS Twitter account for a week?}

In October 2017, there were around 23,000 followers of the @NHS account which is curated by a different person every week. That can be someone working in the NHS or a service user or coming from any connection with the NHS.

As the first dentist, I focused on children's oral health. It was a wonderful opportunity to engage with completely different groups even a lifetime! It's a complementary, highly effective way of interacting and sharing messages. The number of followers went up by about a thousand during the week. I understand that one of my tweets was in the Top ten for the whole year in terms of user engagement.

\section{What has the work of your Managed Clinical Networks (MCNs) - self- supporting groups of professionals working together to ensure cross- speciality sharing of patients and expertise - achieved?}

I chair the Managed Clinical Network for Paediatric Dentistry in Greater Manchester; we are one of the established MCNs in paediatric dentistry in the country. I am also coordinating the chairs of those MCNs nationally.

I think that the whole subject of commissioning is pretty poorly understood and people are almost too busy doing their day jobs to start learning about it. It's not for everybody but there needs to be somebody or a group of professionals within each area that steps up because we either engage with it, or it happens without us and the latter is disastrous.

I have welcomed the opportunity to work with clinicians and teams across a large area who all serve different populations who have different challenges but also to learn from each other and share the resources that we have.

An example. With our MCN, one of our challenges has been to reduce the waiting time for our children needing multiple teeth taken out under general anaesthetic. One of the things we've done is pool resources. For example, if one trust is struggling to get patients through because they haven't got enough anaesthetists and another one might have everything they need apart from theatre time, if you can put all the different pieces of the theatre jigsaw together, you get a whole.

We have shared resources. It's a different way of doing things and it's not immediately comfortable, especially for management teams, but if you can overcome that, it can deliver really positive benefits for our patients. When I started the work, we had a number of hospitals running over a year for waiting times, but now we've only got one provider that is over six months. Lots done, but lots still to do.

It's been a steep learning curve in terms of what is expected of me and how dentists should work with commissioners and consultants in dental public health to deliver change and improve the quality of the services that we deliver to the population.

\section{What have your biggest achievements been during your time as President of the BSPD?}

The biggest achievement has been within Dental Check by One and the fact that we are already starting to see record numbers of young children accessing NHS dental services and alongside that, the feedback that the profession is actually enjoying it and engaging with it. We are starting to see those results coming through. To deliver positive change within a year, is a massive highlight for me and also the fact that three years ago, before I began managing the media team for BSPD, paediatric dentists and the importance of children's oral health were just not recognised. 